\title{
Better in the dark: two Mediterranean amphibians synchronize reproduction with moonlit nights
}

\author{
L. Vignoli ${ }^{1,3}$ and L. Luiselii ${ }^{2,4}$ \\ ${ }^{1}$ Dipartimento di Scienze, Università Roma Tre, Viale Marconi, 446, 00146, Rome, Italy \\ ${ }^{2}$ Centre of Environmental Studies DEMETRA s.r.1., Via Olona 7, 00198, Rome, Italy \\ ${ }^{3}$ Center for Evolutionary Ecology, Largo San Leonardo Murialdo, 1, 00146, Rome, Italy \\ ${ }^{4}$ E.N.I. S.p.a., Environmental Department, Rome, Italy \\ Correspondence to: L. Vignoli (leonardo.vignoli@uniroma3.it)
}

\begin{abstract}
Received: 27 August 2012 - Revised: 21 November 2012 - Accepted: 27 November 2012 - Published: 4 January 2013
\end{abstract}
\begin{abstract}
In Amphibians, both positive and negative correlations between activity and full moon phase have been observed. In this study, we present data for two anuran species (Hyla intermedia and Rana dalmatina) studied in a hilly Mediterranean area of central Italy. We analysed, in a two-year survey, the relationships between the number of egg clutches laid each night and the moon phases by means of circular statistics. Moreover, the studied species exhibited clear oviposition site selection behaviour influenced, at least in $H$. intermedia, by moon phases. We observed the occurrence of an avoidance effect by amphibians for oviposition and specific egg-laying behaviour during moon phases around the full moon. This apparent lunar phobia was evident in both species when yearly data were pooled. On the other hand, while this pattern continued to be also evident in H. intermedia when single years were considered, in R. dalmatina it stood just in one year of study. Nonetheless, during cloudy nights, when moonlight arriving on the ground was low, the frogs' behaviour was similar to that observed in new moon phases. We interpreted the observed pattern as an anti-predatory strategy. Overall, comparisons between our own study and previous research suggest that there was insufficient evidence to establish any unequivocal patterns and that further research in this regard is needed.
\end{abstract}

\section{Introduction}

The effects of the moon on animal biology and behaviour have widely been recognised in several animal groups, including terrestrial vertebrates (i.e. Farbridge and Leatherland, 1987; Bentley et al., 2001; Naylor, 2001; Parson et al., 2003), and marine and intertidal animals, with evidence that most moon-related adaptations are regulated by an internal clock (Morgan, 2001). Some nocturnal terrestrial animals alter their behaviour and activity with changing light conditions in connection with the lunar cycle, this pattern being presumably shaped by antipredatory strategies (e.g. Daly et al., 1992; Julien-Laferrière, 1997; Brooke et al., 2000; Dixon et al., 2006; Campbell et al., 2008). For mammals and birds the lunar periodicity of behaviour is well studied (i.e. Kotler, 1984; Nelson, 1989; Penteriani et al., 2011), while amphibians have remained less investigated (but see Tuttle and Ryan, 1982; Baugh and Ryan, 2010).
Amphibian biology is influenced by not only climate and seasonality (Gibbons and Bennett, 1974), but also by sun and lunar phases for orienting, migrating, breeding and development (e.g. Church, 1960a, b; Landreth and Ferguson, 1967a, b; Fitzgerald and Bider, 1974; Robertson, 1978; Cummings et al., 2008; Baugh and Ryan, 2010). Although moon effects on amphibian biology have been recognized (Church, 1960a, b; Byrne, 2002; Grant et al., 2009), the direction of this influence is rather controversial with evidence of both increased (Tuttle and Ryan, 1982; Grant et al., 2009; Yetman and Ferguson, 2011), and decreased activity under the full moon (Ralph, 1956; Church, 1960b; Fitzgerald and Bider, 1974; Duellman and Trueb, 1994). Concerning anurans, it has been observed that they were able to respond directly to changing moonlight (antipredator and/or foraging behaviours; Kotler et al., 1991), or may present an endogenous cycle with lunar periodicity (Ralph, 1957). 
Our aims in this paper are to present original field data on the influence of moon phases on the reproductive activity of two anuran species (Hyla intermedia and Rana dalmatina) from a hilly Mediterranean area in central Italy. More specifically, we pose the following key questions: (1) Are the study species influenced by moon phases in terms of the reproductive phenology and the oviposition site selection? (2) Does cloudy weather, with the amount of moonlight reaching the ground being scarce also during the full moon phase, shape frog activity in a similar way as a new moon phase does?

\section{Methods}

\subsection{Study area}

The field work was carried out at Canale Monterano ( 190 m a.s.1.; $46.8107^{\circ} \mathrm{N}, 6.7181^{\circ} \mathrm{E}$ ) in the Regional Natural Reserve of Monterano (Province of Rome, Italy). Samples were taken over an area of five hectares within a tuff quarry abandoned for about $30 \mathrm{yr}$. The peculiar permeability properties of tuffaceous substrate allowed the formation of some lentic aquatic habitats fed predominantly by rainfall (Vignoli et al., 2007a).

The study area, consisting of two connected ponds with a surface area of about $1500 \mathrm{~m}^{2}$ each, was surveyed periodically in 2001-2003 (data were partially published in Vignoli et al., 2007a, b, 2009), with a minimum survey effort of once a month during late summer and autumn, and a maximum frequency of two visits per week in late winter and spring when most species had their activity peaks. Aquatic vegetation consisted of Chara sp., Juncus sp., Carex sp., and Ranunculus aquaticus. Samplings were done at intervals of at least two days. We avoided sampling the study area daily to reduce the non-independent effects of the contiguous sampling dates.

The study site was far from human settlements (Vignoli, 2003); thus, there were no sources of ecological light pollution (Longcore and Rich, 2004; Baker and Richardson, 2006) strong enough to disrupt the amphibian responses to moonlight, if any. Unfortunately, during samplings a luxmeter was unavailable. However, in 2009 we measured at the study site the amount of light reaching the ground under full moon and new moon phases by using a luxmeter (Lafayette DT-8820) assuming that the same light conditions (in relation to moon phase) would have occurred also during the field study period. The light measured at the ground under clear sky condition was (mean \pm SD) $0.018 \pm 0.009$ lux $(n=11)$ and $0.098 \pm 0.054$ lux $(n=9)$ under, new and full moon phases, respectively. No statistically significant differences were detected in cloudy or rainy nights $(0.027 \pm 0.017)$ between moon phases in terms of the amount of moonlight reaching the ground $(U=3.0 ; n=19 ; p=0.51$; U-test $)$.

\subsection{Protocol and data analyses}

In this study we have analyzed data from $H$. intermedia and $R$. dalmatina, which are characterized by open wateroviposition (Vignoli et al., 2007a). Oviposition data were collected via Visual Encounter Survey, in 2001 and 2003 for $R$. dalmatina and 2002-2003 for $H$. intermedia, from January to June. For each sampling, we recorded the moon phase and the weather conditions (i.e. cloud cover degree, and rainfall) of the night before each date of survey. The study site was surveyed on 21 distinct dates for $R$. dalmatina ( 5 in full moon, 4 in third quarter, 5 in new moon, and 7 in first quarter) and on 13 distinct dates for $H$. intermedia (3 in full moon, 4 in third quarter, 4 in new moon, and 2 in first quarter). Hence, there was no unequal sampling according to the moon phase (for both species: $\chi^{2} \leq 0.41$; $\mathrm{df}=3 ; p \geq 0.82$. Yates's chi-squared test). At each visit conducted in the morning, we checked all the clutches laid the night before, assuming that one mating pair corresponded to one clutch (Paton and Harris, 2010). Moreover, for $H$. intermedia in 2003, we recorded the water temperature around the main clutch groups, this being a crucial parameter affecting the reproductive output success by influencing the egg and embryo development (Duellman and Trueb, 1994). We avoided to carrying out samplings after nights of heavy rain because of the uncontrolled influence that this perturbation potentially has on mating activity and because of the water turbidity that limits the clutch recognition in the morning after. The nights characterized by normal rainfall were included in the sample. In the analyses we used the number of oviposited clutches per night as a descriptor of anuran activity (Adams et al., 1998; Lipps et al., 2001; Rödel and Ernst, 2004; Paton and Harris, 2010). The embryo stage (Gosner, 1960; Gosner and Rossman, 1960) and the degree of egg jelly capsule hydration (an indirect measure of the time elapsed by eggs into water) was used to recognize whether each egg mass had been deposited the day before the sampling (estimated precision: \pm 1 day) or in previous dates. The two study species show one reproductive event per year, the reproductive season lasting around two months (at the study site usually ranging January-March for $R$. dalmatina, and March-May for $H$. intermedia. Vignoli et al. (2007a), with males arriving earlier and outnumbering females (Bernini et al., 2007; Lapini, 2007). All these features facilitate the recognition of actual spawning numbers (Paton and Harris, 2010). In addition, both species are suitable to be sampled by egg mass counts because they (i) show welldefined reproductive phenology at the study site (Vignoli et al., 2007a); (ii) they lay eggs in small wetlands (Vignoli et al., 2007b), so that samplers can survey sites completely (Paton and Harris, 2010); (iii) they breed in relatively cold months (late winter and spring; Vignoli et al., 2007a), have hatching rates slow enough to allow easy sampling and embryo stage recognition (Paton and Harris, 2010); (iv) they attach the eggs to plants or other immersed material; and (v) oviposition sites are located in shallow sections of the wetlands 
(Vignoli et al., 2007b), simplifying clutch recognition (Wells, 2007). Since $H$. intermedia may lay the eggs in both one large single clutch or in several smaller clumps, we tried to limit the potential overestimation of actual oviposition by considering only masses $\geq 50$ eggs.

Because oviposition site selection optimizes egg/larvae/young survival compared to non-selection (Schwarzkopf and Brooks, 1987), in 2003 we analysed the reproductive period's clutch distribution (degree of aggregation and micro-habitat choice) within a portion of the study ponds in relation to lunar phase in order to ascertain if the moon influences the oviposition behaviour. The position of each clutch was analysed in terms of reciprocal distance with all the other clutches laid in the same sampling date. We also recorded the micro-habitats where amphibians laid their eggs, classifying the selected habitats into two main groups: shallow waters ( $29.8 \%$ of total pond surface) and aquatic emerging vegetation (mainly consisting of Juncus sp.) (1.1\% of total pond surface) (Vignoli et al., 2007b).

We considered, as environmental factors potentially affecting anuran reproductive activity, the cloud cover (the night before the clutch sampling), rainfall events (the day before the clutch sampling), and the water temperature (Duellman and Trueb, 1994). We did not analyse air temperature, which could of course have an effect on reproduction. However, we were interested in discovering patterns of anuran spawning activity variations over relatively short periods (onetwo months) rather than investigating which factors influence the reproductive biology as a whole; thus the short-term effects of air temperature are probably minor. Temperature is demonstrated to be a weak predictor of reproductive activity for winter and early spring temperate anuran breeders (such as our two study species; Oseen and Wassersug, 2002), because they are in general physiologically adapted to cold water (Salthe and Mecham, 1974; John-Alder et al., 1988) and can behaviourally mitigate the effects of low temperature by laying eggs in the shallower areas of the ponds that warm up more quickly (Van Gelder and Hoedemaekers, 1971; Vignoli et al., 2007b). The influence of such environmental parameter is more closely related to the timing when the populations begin the reproductive activity rather than to the activity modulation once the animals have reached the breeding site and the reproduction has already begun (Duellman and Trueb, 1994; Oseen and Wassersug, 2002; Canavero and Arim, 2009).

\section{Statistical analyses}

We analysed amphibians' phenological data by means of circular statistics, coupling data on reproductive activity with lunar periodicity, assigning to each sampling date a value in the range $0-29$, where 0 represents the full moon. Lunar day values were converted to angles by dividing the length in days of the synodic lunar cycle (29.5) and then multiplying by $360^{\circ}$. The number of oviposited clutches observed on a given lunar day was converted to frequencies of each an- gle observed. The following parameters were estimated for each species: (i) the mean vector $(\boldsymbol{\mu})$, which corresponds to the mean angle (lunar day) around which most mating pairs were spawning; (ii) the circular standard deviation; (iii) the length of the mean vector $(r)$ as a measure of vector magnitude; (iv) $95 \%$ confidence intervals (CI) for $\boldsymbol{\mu}$; and (v) the concentration, a measure of data concentration around the considered cycle. We performed the analyses on both separated and pooled years in order to reduce the risk of not finding a pattern due to annual factors not under our control.

In order to assess whether amphibian reproductive activity (number of laid clutches) has an uniform distribution or follows a specific pattern (i.e. lunar ciclicity), we used Rao's spacing test, an equivalent of a non-parametric test of classic statistics (phenological data were not normally distributed), for testing data aggregation along lunar cycle, and V-test for testing data distribution against a specified angle (Batschelet, 1981). For all the study species we tested our two $\mathrm{H}_{1}$ hypotheses that (i) reproductive activity is not uniformly distributed along the lunar cycle $\left(\mathrm{H}_{1 \mathrm{~A}}\right)$, and (ii) follows a lunar periodicity concentrating around new moon phases (expected mean $\left.180^{\circ}\right)\left(\mathrm{H}_{1 \mathrm{~B}}\right)$, against the $\mathrm{H}_{0}$ hypotheses that (i) reproductive events are randomly spaced throughout the lunar cycle $\left(\mathrm{H}_{0 \mathrm{~A}}\right)$, and (ii) full moon phases stimulate spawning activity (expected mean $\left.360^{\circ}\right)\left(\mathrm{H}_{0 \mathrm{~B}}\right)$. We tested all the datasets for a specific angle using alternatively four expected means (the four quarters of the synodic lunar cycle). Moreover, we analysed the study species' reproductive activity taking into account sky conditions. As we expected amphibian spawning activity to be mainly driven by moonlight, we also tested the above hypotheses by considering all the sampled cloudy nights (sky completely covered by clouds), and the reproductive output recorded the morning after, as falling in low light lunar phases (e.g. new moon). Although this approach clearly produces artefacts in the observed spawning activity, it could reveal patterns otherwise masked by the variable moonlight reaching the ground due to cloud cover.

A Multi Response Permutation Procedure (MRPP) was applied on the clutch distribution in order to evaluate the significance of inter-moon phase differences. The strategy of MRPP in our case was to compare the observed intramoon phase average clutch distances with the average distances that would have resulted from all the other possible combinations of clutch positions considering all the sampling dates under the null hypothesis (Mielke et al., 1976). The test statistic $(\delta)$ is the average of the observed intragroup distances weighted by relative group size. Oviposition site selection behaviour (micro-habitat use as compared to its availability within the pond) was put in relationship with lunar cycle by means of contingency tables $(4 \times 2$ : four phases by two micro-habitats) and Chi-square tests. Relationships between the number of observed oviposited clutches and water temperature and rainfall events were tested by means of Spearman rank correlation and Mann-Whitney U-test, respectively. All circular data were analysed using the software 


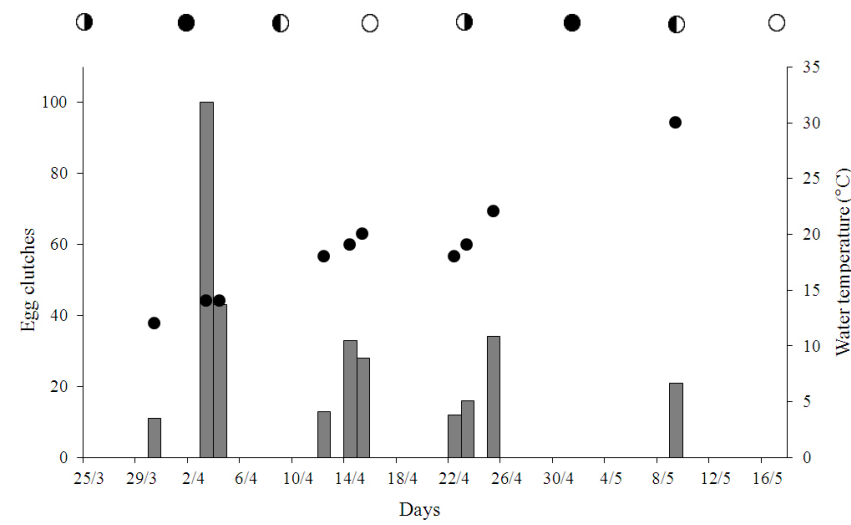

Figure 1. Number of oviposited clutches by Hyla intermedia (bars) and water temperature (black circles) at the study site in 2003. Moon phases are also displayed.

Oriana (version 3.11; Kovach Computing Services, 2011; http://www.kovcomp.com). The MRPP analyses were performed by using Blossom software (version W2008.04.02; http://www.fort.usgs.gov/products/software/blossom/).

\section{Results}

\subsection{Reproductive patterns}

By and large, considering the study years pooled, we observed 354 clutches of $H$. Intermedia and 370 clutches of $R$. dalmatina. Oviposition activity of both species did not differ between rainy and dry conditions ( $R$. dalmatina: rainy/dry days $=4 / 17 ; U=15.5 ; p=0.10$. $H$. intermedia: rainy/dry days $=2 / 11 ; U=2.0 ; p=0.07)$. There was no relationship between oviposited clutches and water temperature in $H$. intermedia ( $r=0.12 ; n=10 ; p=0.73$ ) (Fig. 1). There was an interspecifically consistent pattern regarding how the two studied species responded to moon phases (Figs. 2 and 3; Table 1). The $\mathrm{H}_{0}$ hypotheses were both rejected when tested against both our $\mathrm{H}_{1}$ hypotheses, that is: (i) in the studied species, ovipositions were not uniformly distributed and (ii) did not deviate from a mean angle of $180^{\circ}$ (new moon phase) (Table 1). In both species there was a strong positive relationship between number of oviposited clutches and low light intensity moon phases (new moon and adjacent phases). Indeed, the oviposition activity peaked during the transition phase between new moon and 1st quarter (waxing moon; ranges: $224.1-250.4^{\circ}$ for $R$. dalmatina and $200.0-222.7^{\circ}$ for H. intermedia; Figs. 2 and 3; Table 1).

When we analyzed the dataset yearly, we found in each year consistent trends with the results coming from pooled years at least for one studied species (Table 1). For H. intermedia there was no inter-annual difference in clutch temporal distribution (Fig. 2). Concerning R. dalmatina the annual patterns differed remarkably. Indeed, whilst in 2003 the pattern was consistent with that coming from yearly datasets pooled, in 2001 there was no recognizable pattern (Fig. 3). The analyses of the observed clutch distribution in conjunction with information on cloud cover gave the same results obtained without it (data not shown for brevity), apart from one year for $R$. dalmatina. When the clutch distribution of $R$. dalmatina in 2001 was analyzed taking into account the cloud cover, the egg laying activity pattern appeared to be concentrated around the new moon phase, similarly to results obtained for the same species in 2003 and for $H$. intermedia in both years (Fig. 3). Rao's spacing test revealed aggregated distribution for all the used datasets (both the species, yearly and pooled). Nonetheless, $R$. dalmatina, in 2001, showed an overdispersed distribution of clutches along lunar cycle, thus determining the unreliability of the statistics (Table 1). None of the datasets' distributions deviated from a mean angle of $180^{\circ}$ (new moon phase; for all tests: $u \geq 4.50$ and $p<0.0001$; V-test) except for $R$. dalmatina in 2001 (Table 1). Moreover, clutch distributions over time showed also a concentration around $270^{\circ}$ (1st quarter; for all tests: $u \geq 2.13$ and $p \leq 0.02$ ) although less evident than that at $180^{\circ}$, whereas during the remaining two quarters $\left(0^{\circ}\right.$ and $90^{\circ}$, respectively full moon and 3rd quarter) the occurrence of clutches was lower (for all tests: $u \leq 1.32$ and $p \geq 0.08$ ).

\subsection{Egg laying behaviour}

As regards $R$. dalmatina, there was no inter-moon phase difference in terms of egg clutch distribution (data from a single study pond: average group distance $\delta_{\text {obs }}-\delta_{\exp }=$ $-0.009 ; p>0.05$. MRPP). We did not observe any oviposition site preference (with a significant prevalence of egg masses laid in the shallow waters of the study ponds) $\left(\chi^{2}=11.7 ; \mathrm{df}=3 ; p<0.01\right)$. On the other hand, H. intermedia showed a moon phase-dependent egg laying behaviour in terms of (i) clutch distribution and (ii) micro-habitat selection for oviposition. In more detail, (i) the clutches laid under full moon showed an average distance significantly less than that expected by chance (data from a single study pond; average group distance $\delta_{\text {fullmoon }}=0.72 \mathrm{~m}$, $\delta_{\text {newmoon }}=1.59 \mathrm{~m} ; \delta_{\text {obs }}-\delta_{\text {exp }}=-2.33 \mathrm{~m}, \delta_{\text {variance }}=0.0005 \mathrm{~m}$; $p<0.00001$; Fig. 4); (ii) mating pairs showed a non-random and non-homogeneous among-moon-phases use of microhabitats for oviposition $\left(\chi^{2}=78.7\right.$; $\mathrm{df}=3 ; p<0.0001$; Contingency table), exhibiting a significant preference for laying eggs towards the micro-habitat under the aquatic emerged vegetation (Juncus sp.) under full moon $\left(N=61 ; \chi^{2}=243\right.$; $\mathrm{df}=1 ; p=0$ ), whereas shallow waters was the most preferred habitat type during the remaining lunar phases (for all tests: $\chi^{2} \geq 4.2 ; \mathrm{df}=1 ; p \leq 0.03$ ).

\section{Discussion}

Our data clearly showed a reproductive phenology nonrandomly related to lunar cycle, with both species concentrating spawning activity between the new moon and 
Table 1. Synopsis of the circular statistics for the clutch distribution in two species of amphibians at a locality in Mediterranean Central Italy. For each species yearly and pooled data are reported. The statistical tests refer to whether or not clutches are laid uniformly over the lunar cycle (Rao spacing test) and whether or not clutch distribution have a mean angle (expected mean 180 ${ }^{\circ}$ ) (V-test) (Batschelet, 1981). For Rana dalmatina, the column $2001^{*}$ showed the analysis taking into consideration also the cloud cover (see methods).

\begin{tabular}{|c|c|c|c|c|c|c|c|}
\hline & \multicolumn{4}{|c|}{ R. dalmatina } & \multicolumn{3}{|c|}{ H. intermedia } \\
\hline & 2001-2003 & 2001 & $2001^{*}$ & 2003 & $2002-2003$ & 2002 & 2003 \\
\hline$N$ of observations & 370 & 182 & 182 & 187 & 354 & 32 & 322 \\
\hline Mean vector $(\boldsymbol{\mu})$ & $237.3^{\circ}$ & $300.0^{\circ}$ & $163.5^{\circ}$ & 224.3 & $201.9^{\circ}$ & $203.2^{\circ}$ & $201.7^{\circ}$ \\
\hline Length of $\boldsymbol{\mu}(r)$ & 0.31 & 0.14 & 0.34 & 0.55 & 0.36 & 0.68 & 0.33 \\
\hline $95 \%$ C.I. $( \pm)$ for $\mu$ & $224.1-250.4^{\circ}$ & n.c. & $146.8-180.2^{\circ}$ & $214.8-233.9^{\circ}$ & $190.7-213.2^{\circ}$ & $185.5-220.9^{\circ}$ & $188.7-214.7^{\circ}$ \\
\hline Concentration & 0.66 & 0.29 & 0.73 & 1.33 & 0.78 & 1.86 & 0.70 \\
\hline Circular S.D & $88.1^{\circ}$ & 112.9 & $83.9^{\circ}$ & 62.2 & $81.7^{\circ}$ & $50.7^{\circ}$ & $85.3^{\circ}$ \\
\hline Rao's spacing test $(U)$ & 343.6 & 340.2 & 346.1 & 338.9 & 349.8 & 326.2 & 351.0 \\
\hline Rao's spacing test $(p)$ & $<0.01$ & $<0.01$ & $<0.01$ & $<0.01$ & $<0.01$ & $<0.01$ & $<0.01$ \\
\hline V-test $\left(V \exp .180^{\circ}\right)$ & 0.17 & -0.07 & 0.33 & 0.40 & 0.33 & 0.62 & 0.31 \\
\hline V-test $(u)$ & 4.50 & -1.37 & 6.24 & 7.67 & 8.93 & 4.97 & 7.79 \\
\hline V-test $(p)$ & $<0.0001$ & 0.91 & $<0.000001$ & $<0.0001$ & $<0.0001$ & $<0.0001$ & $<0.0001$ \\
\hline
\end{tabular}

n.c.: not calculated due to the very low data concentration
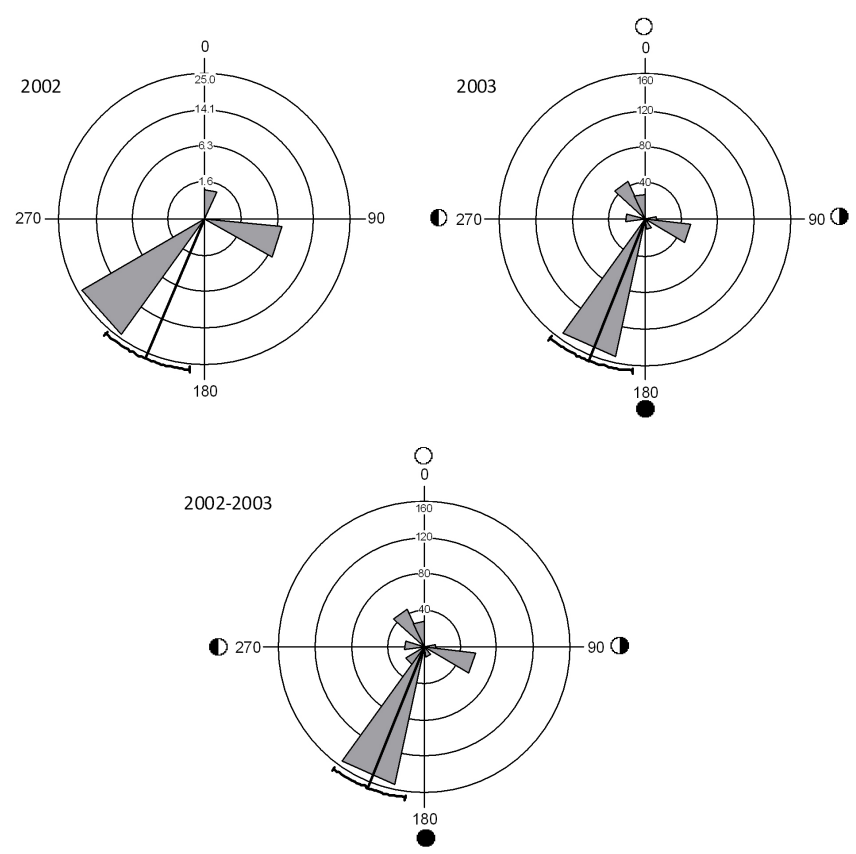

Figure 2. Patterns of reproductive phenology in Hyla intermedia in relation to lunar cycle at the study locality in Mediterranean Central Italy. Datasets from 2002, 2003 and pooled years are shown. Area of wedges represents the number of egg clutches (each one considered a proxy of a single pair in spawning activity) laid during a single night. Concentric dotted lines represent the scale for the number of egg masses (numbers only on the top axis). Black ray indicates the mean vector $(\boldsymbol{\mu})$ and the external black curved line represents $95 \%$ confident intervals (in grey if the statistic was unreliable). $0^{\circ}=$ full moon; $180^{\circ}=$ new moon.
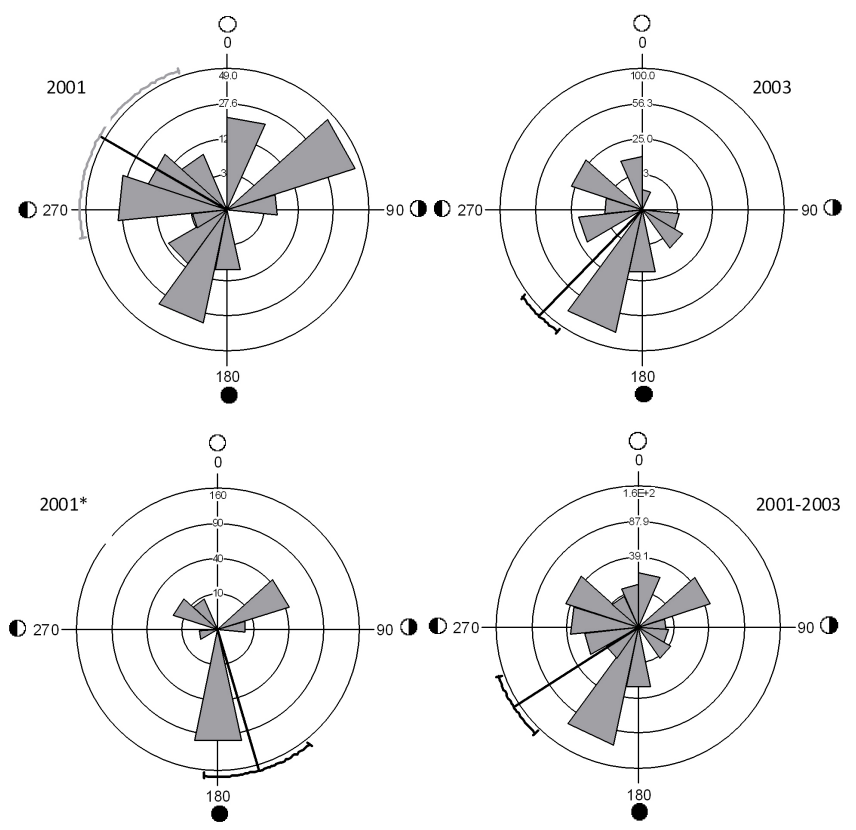

Figure 3. Patterns of reproductive phenology in Rana dalmatina in relation to lunar cycle at the study locality in Mediterranean Central Italy. Datasets from 2001, 2001 with cloud cover information $\left(2001^{*}\right), 2003$ and pooled years (2001-2003) are shown. Area of wedges represents the number of egg clutches (each one considered a proxy of a single pair in spawning activity) laid during a single night. Concentric dotted lines represent the scale for the number of egg masses (numbers only on the top axis). Black ray indicates the mean vector $(\boldsymbol{\mu})$ and the external black curved line represents $95 \%$ confident intervals (in grey if the statistic was unreliable). $0^{\circ}=$ full moon; $180^{\circ}=$ new moon. 

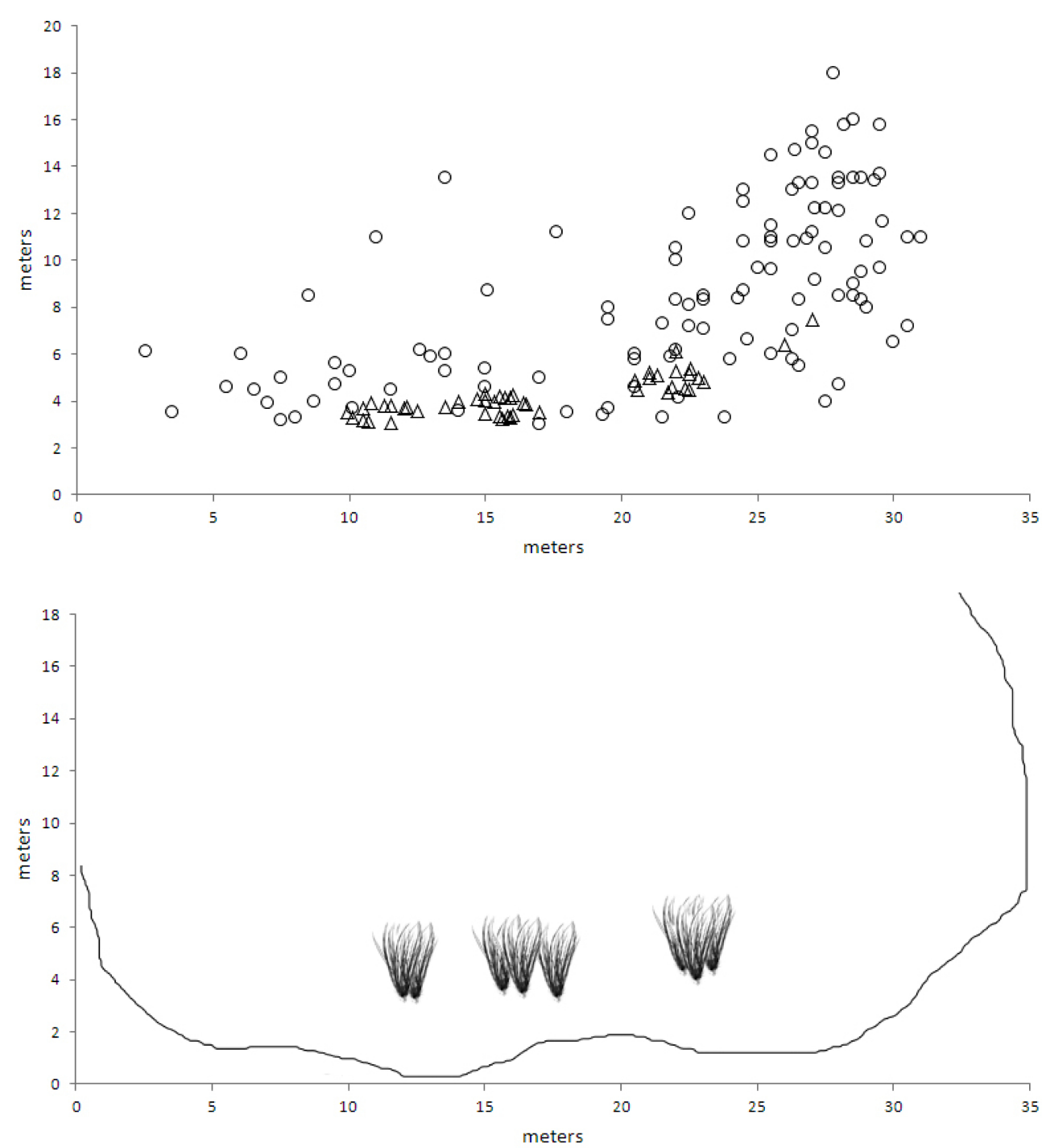

Figure 4. (A) Clutch distribution of Hyla intermedia in one of the study ponds. Circles $(N=110)=$ clutches laid during new moon; Triangles $(N=48)=$ clutches laid under full moon. (B) Pond profile (black line) with detailed location of emerging aquatic vegetation.

1st quarter phases (waxing moon). Our study hence mirrors earlier studies documenting that amphibian reproductive phenology is influenced by the moon cycle (e.g., Tuttle and Ryan, 1982; Duellman and Trueb, 1994; Grant et al., 2009; Yetman and Ferguson, 2011); it does differ, however, from the findings of Grant et al. (2009), who observed a peak of activity around full moon in other anuran species from temperate regions (Grant et al., 2009). We also found that oviposition site selection was, at least in $H$. intermedia, clearly influenced by moon phase (= lunar phobia behavior).

\subsection{Reproductive patterns}

Overall, no relationship was found between rainfall, water temperature and clutch oviposition. Recent studies (Both et al., 2008; Canavero et al., 2008; Canavero and Arim, 2009) demonstrated that the invoked role of rainfall as determinants of temperate amphibian activity has been overemphasized (Duellman and Trueb, 1994; Stebbins and Cohen, 1997). However, it is well known that rainfall may affect breeding pond amphibian activity, at least at fine spatial and temporal scales (i.e. migration towards the reproductive sites) (Pechmann and Semlitsch, 1986; Oseen and Wassersug, 2002; Semlitsch, 2008). Indeed, we expected a possible effect of this parameter on the analyzed metrics due to the increased rate of newly arriving individuals at the ponds during rainy nights. However, an increased amphibian activity could be related to the increasing air humidity (Martof, 1953) during cloudy nights also without rain (i.e. chorusing; L. Vignoli, unpublished data).

As far as the influence of the moon is concerned, our data mirror those for the nearctic Rana cancrivora, which 
showed the highest average ovarian weight during new moon and the smallest under full moon (Church, 1960b), and for the neotropical Engystomops (= Physalaemus) pustulosus regarding to the nocturnal phenology (Jaeger and Hailman, 1981). Moreover, Baugh and Ryan (2010) concluded that the behavioral variation (mate choice) due to the perceived predation risk by E. pustulosus females was higher under moonlit conditions than during a new moon phase. Other studies also reported reduced activity (albeit not strictly related to reproduction) during full moon, including depressed movements in Bufo americanus (Fitzgerald and Bider, 1974), and peaks of captures of newts during the darkest phase of the moon (Deeming, 2008). These patterns were interpreted as antipredatory behavior.

Assuming that the full moon corresponds to the peak of the light reaching the ground at night time, and the new moon to the minimum (Krisciunas and Schaefer, 1991), our results indicate a depressed reproductive activity in Rana dalmatina and Hyla intermedia during phases of high moonlight intensity. This was evident with both yearly data pooled or taken separately in $H$. intermedia (in both years) and with yearly data pooled and in one of the years in $R$. dalmatina. Nevertheless, also in the single year without significant pattern, when cloud cover (i.e. a factor influencing the resultant moonlight intensity on the ground) was included in the analysis, we obtained a consistent pattern of depressed activity during conditions of strong light on ground. We speculate that, when there is cloudy weather also during full moon, the frogs are incapable of distinguishing one lunar phase from another just by perceiving the light intensity alone. Therefore, by analyzing the lunar phases as the only constraint conditioning spawning activity, the effective intensity of reproductive events under low-light conditions is likely underestimated. Since $R$. dalmatina breeds during late winter-early spring (when cloudy weather normally occurs at the study area; Mantero, 2006), we hypothesize that, in 2001, the type of pattern observed in 2003 may have been skewed by the occurrence of cloudy nights under full moon phases.

Moreover, a closer inspection of our circular plots revealed that the distribution of clutches for both species was nonsymmetric around the $180^{\circ}$ degree mark, as expected if the study species spawning activity was merely regulated by an avoidance of high light on ground, but concentrated immediately after the new moon phase. Interestingly, it appeared that the down peak of light under new moon could trigger spawning. Hence, the females could approach the pond and join the males, arrived earlier in the season, only once the light conditions allow frogs to migrate to the pond and start spawning with a reduced risk of predation. This scenario becomes more complex if intra-night variation of light intensity is also considered: during one night there may be a portion of the time with higher lunar illumination (moon rising) and the remaining with lower or no illumination (moon down). There is evidence that intra-night variation of moonlight intensity affects surface activity of small mammals (Lockard and Owings, 1974); also anurans are probably able to modulate reproductive activity (i.e. chorusing, mate searching, oviposition) throughout the night time once they have started to spawn at the breeding site. It is, however, possible that, if amphibians are guided by an endogenous lunar rhythm, they may respond to lunar phase regardless of cloud cover and light intensity. This hypothesis is unlikely in $R$. dalmatina given the inter-annual differences found in its reproductive patterns.

To our knowledge, the only other study exploring the effects of lunar cycle on reproductive activity of temperate anurans is by Grant et al. (2009). Although these authors found that various aspects of anuran reproductive phenology (in Bufo bufo, Pelophylax spp.) were intensified around the full moon, we found in our own two study species quite the contrary to be the case. We speculate that the observed differences may be due to (i) species-specific effects and/or (ii) a suite of methodological issues, including type of descriptors used and interpretation of statistical analyses.

\subsection{Egg laying behaviour}

Both study species showed oviposition-site selection in laying eggs in micro-habitats that differed from random habitats within the study ponds. Rana dalmatina exhibited a consistent micro-habitat selection for oviposition (shallow waters) and clutch distribution irrespective of the lunar phase, whereas $H$. intermedia showed a clear choice (shallow waters vs. aquatic emerging vegetation) to where laying eggs and different patterns of clutch aggregation in relation to lunar phase. For this latter species, the clutches laid around full moon aggregated below emerging rush tussocks (Juncus sp.), while during the remaining phases the ovipositions were positioned in free shallow waters. In other words, during full moon mating pairs apparently selected well vegetated spots as oviposition sites and avoided lowly vegetated sites. Although our study species do not build nests, we consider the observed behavior to be similar to true nestsite selection as in other egg laying amphibians (see Petranka, 1990; Brown and Iskandar, 2000; Dillon et al., 2000). Nest-site selection behaviours may increase embryo protection from predation (Resetarits and Wilbur, 1989), competition (Dillon et al., 2000), parasitism (Kiesecker and Skelly, 2000), and/or environmental factors (Bragg et al., 2000), thus enhancing embryo survivorship (Schwarzkopf and Brooks, 1987). Another primary outcome of oviposition site selection behaviours could be the enhancement for a mating pair to successfully complete the mating process. In our case, under the lightest moonlit conditions $H$. intermedia spawning couples apparently made a non-random selection of the micro-habitats in order to ensure the best protection from visually oriented predators. Indeed, during spawning activity, most anurans face a very high risk of predation because of the higher vulnerability of a mating pair in respect to a single individual (Olson, 1989). Hence, anurans may exhibit a 
suite of behavioral adaptations to the need of avoiding predation, including alterations in the temporal activity patterns (e.g. Lima and Dill, 1990; Murray et al., 2004). Presumably, at our study site the predation pressure that mating pairs of $H$. intermedia undergo during spawning periods is higher than that faced by $R$. dalmatina (see below). This is due to the increased number of potentially active predators occurring in springtime, when the tree frogs spawn, as compared to late winter, when agile frogs lay eggs. Moreover, $H$. intermedia reproductive behavior makes individuals likely more conspicuous (males calling perched on a substrate outside water or on water surface; L. Vignoli, pers. obs.) than those of $R$. dalmatina (males usually calling from underwater; Schneider et al., 1988).

\subsection{Reproductive strategy}

The interplay of moonlight and animal's nocturnal behavior, especially for prey, is not a zero-one phenomenon (either be active or not), but a continuum of states that correspond to different levels of activity, involving a trade-off between activity and safety. Regarding reproduction, animals often undergo increased predation risk due to enhanced conspicuousness to predators (Magnhagen, 1991). As for the amphibians, the risk of predation varies in time and space, influencing in a number of ways the various phases of reproduction (site approaching, mate searching) and actors involved (calling males, fighting males) (Lima and Dill, 1990). Therefore, individuals should adjust their reproduction behavior according to changes in predation risk (Lima and Dill, 1990). In amphibians the chance of reproduction and the risk of predation while spawning are two important factors that interact to define both spatial and temporal patterns. That is, to maximize the reproductive success, amphibians have to balance their decisions on when, where and how to reproduce against predation risk (Lima and Dill, 1990; Magnhagen, 1991).

We speculate that an antipredatory strategy could be among the factors underlying the observed patterns. Indeed, $H$. intermedia is intensely hunted by grass snakes (Natrix natrix), a mainly visually oriented predator, at the study area during nighttime (Luiselli et al., 2005). The same is not true for $R$. dalmatina, which spawns before the onset of grass snakes' period of foraging activity (late March, Luiselli et al., 2005). Both species can also be eaten by nocturnal birds of prey during the reproductive period (Jaksic et al., 1982). Moreover, lunar-related activity patterns similar to those observed in this study (lunar phobia) have been described for other amphibians (i.e. Ralph, 1957; Fitzgerald and Bider, 1974) as well as for several nocturnal animals (scorpions Skutelsky, 1996; snakes - Campbell et al., 2008; mammals - Lockhard, 1978; Wolfe and Tan Summerlin, 1989; Daly et al., 1992; Gannon and Willing, 1997; birds - Clarke, 1983; Mougeot and Bretagnolle, 2000). In all these studies, the observed moonlight avoidance by animals has been related to the increasing risk of predation by visually oriented preda- tors due to bright moonlight (Lima and Dill, 1990). An experimental study revealed a significant effect of moonlight on the microhabitat use by a visually oriented predator (a snake; see Campbell et al., 2008), this adaptation being likely due to both antipredatory strategy and predation avoidance behavior by its prey in habitat selection linked to moon phases.

The activity of nocturnal or cathemeral animals is usually less influenced by moon luminosity because most of them show eye structures enhancing vision in low light (i.e. tapeta lucida) (Nash, 1986; but see Donati et al., 2001). Anurans usually are cathemeral or strictly nocturnal, having a sort of tapetum (most of them showed eye-shine; Walls, 1942). They are mainly acoustically and olfactory oriented animals as regards intraspecific (intersexual) communication and shortdistance orientation to the breeding site (Sinsch, 1990; Duellman and Trueb, 1994). Hence, apart from the anti-predatory strategy, it is possible that visual constraints marginally regulate frogs' nocturnal reproductive activity. However, visual stimuli are important at short distance during nighttime for mate choice in Hyla arborea (Gomez et al., 2009), a species which is genetically closely related to $H$. intermedia.

In conclusion, our study added on two previously unstudied species that moon phases do affect anuran reproductive phenology (see also Tuttle and Ryan, 1982; Grant et al., 2009; Yetman and Ferguson, 2011). In addition to this, our study also highlights discrepancies with earlier studies on species from similar climates and latitudes. This suggests caution is due when trying to generalize about the biological response of amphibian populations to phases of the moon. Clearly further studies are still needed to solve these puzzling issues.

\section{Ethical standards}

We declare that the experiments comply with the current laws of Italy. The Italian Ministry of the Environment gave us the authorization to study amphibians (authorization n. DPN/2D/2003/2267). No animals were damaged or killed during this project, and all were handled according to the standards of the Italian Ministry for Scientific Research and Technology.

Acknowledgements. This research was entirely funded by $\mathrm{L}$ and V ltd. We sincerely thank A. Venchi for suggestions on earlier drafts, Aero P. Babolat and Lindaus Aria for having shared a lot of time in the field, the Bandiera Brothers for useful discussion, and Martin Bennet and Roger Federer for the English revision of the final draft. This paper is dedicated to our friend V. Gerulaitis, who tragically died during a field session.

Edited by: J. Stadler

Reviewed by: two anonymous referees 


\section{References}

Adams, M. H., Bury R. B., and Swarts, S. A.: Amphibians of the Fort Lewis Military Reservation, Washington: Sampling techniques and community patterns, North-western Nat., 79, 12-18, 1998.

Baker, B. J. and Richardson, J. M. L.: The effect of artificial light on male breeding-season behaviour in green frogs, Rana clamitans melanota, Can. J. Zool., 84, 1528-1532, 2006.

Batschelet, E.: Circular statistic in biology, Academic Press, London, 1981.

Baugh, A. T. and Ryan, M. J.: Ambient light alters temporalupdating behaviour during mate choice in a Neotropical frog, Can. J. Zool., 88, 448-453, 2010.

Bentley, M. G., Olive, P. J. W., and Last, K.: Sexual satellites, moonlight and the nuptial dances of worms: the influence of the Moon on the reproduction of marine animals, Earth Moon Planets, 85, 67-84, 2001.

Bernini, F., Guarino, F. B., and Picariello, O.: Rana dalmatina Fitzinger, in Bonaparte, 1838, in: Fauna d'Italia: Amphibia, edited by: Lanza, B., Andreone, F., Bologna, M. A., Corti, C., and E. Razzetti, Bologna, Calderini Edizioni, 404-408, 2007.

Both, C., Kaefer, I. L., Santos, T. G. and Cechin, S. T. Z.: An austral anuran assemblage in the Neotropics: seasonal occurrence correlated with photoperiod, J. Nat. Hist., 42, 205-222, 2008.

Bragg, W. K., Fawcett, J. D., Bragg, T. B., and Viets, B. E.: Nestsite selection in two eublepharid gecko species with temperaturedependent sex determination and one with genotypic sex determination, Biol. J. Linn. Soc., 69, 319-332, 2000.

Brooke, P. N., Alford, R. A., and Schwarzkopf, L.: Environmental and social factors influence chorusing behaviour in a tropical frog: examining various temporal and spatial scales, Behav. Ecol. Soc., 49, 79-87, 2000.

Brown, R. M. and Iskandar, D. T.: Nest site selection, larval hatching, and advertisement calls, of Rana arathooni from southwestern Sulawesi (Celebes) island, Indonesia, J. Herpetol., 34, 404413, 2000.

Byrne, P. G.: Climatic correlates of breeding, simultaneous polyandry and potential for sperm competition in the frog Crinia Georgiana, J. Herpetol., 36, 125-129, 2002.

Campbell, S. R., Mackessy, S. P., and Clarcke, J. A.: Microhabitat use by Brown Treesnakes (Boiga irregularis): effects of moonlight and prey, J. Herpetol., 42, 246-250, 2008.

Canavero, A. and Arim, M.: Clues supporting photoperiod as the main determinant of seasonal variation in amphibian activity, J. Nat. Hist., 43, 2975-2984, 2009.

Canavero, A., Arim, M., Naya, D. E., Camargo, A., da Rosa, I., and Maneyro, R.: Calling activity patterns in an anuran assemblage: the role of seasonal trends and weather determinants, Northwest J. Zool., 4, 29-41, 2008.

Church, G.: Annual and lunar periodicity in the sexual cycle of the Javanese toad, Bufo melanostictus (Schneider), Zoologica, 45, 181-188, 1960a.

Church, G.: The effects of seasonal and lunar changes on the breeding pattern of the edible Javanese frog, Rana cancrivora Gravenhorst, Treubia, 25, 215-233, $1960 \mathrm{~b}$.

Clarke, J. A.: Moonlight's influence on predator/prey interactions between short-eared owls (Asio flammeus) and deermice (Peromyscus maniculatus), Behav. Ecol. Sociobiol., 13, 205-209,
1983.

Cummings, M. E., Bernal, X. E., Reynaga, R., Rand, A. S., and Ryan, M. J.: Visual sensitivity to a conspicuous male cue varies by reproductive state in Physalaemus pustulosus females, J. Exp. Biol., 211, 1203-1210, 2008.

Daly, M., Behrends, P. R., Wilson, M. I., and Jacobsi, L. F.: Behavioural modulation of predation risk: moonlight avoidance and crepuscular compensation in a nocturnal desert rodent, Dipodomys merriami, Anim. Behav., 44, 1-9, 1992.

Deeming, D. C.: Capture of smooth newts (Lissotriton vulgaris) and great crested newts (Triturus cristatus) correlates with the lunar cycle, Herpetol. J., 18, 171-174, 2008.

Dillon, M. E., Fiaño, J., and Price, A. H.: Oviposition Site Selection by the Túngara Frog (Physalaemus pustulosus), Copeia, 2000, 883-885, 2000.

Dixon, D. R., Dixon, L. R. J., Bishop, J. D., and Pettifor, R. A.: Lunar-related reproductive behaviour in the badger (Meles meles), Acta Ethol., 9, 59-63, 2006.

Donati, G., Lunardini, A., Kappeler, P. M., and Borgognini Tarli, S. M.: Nocturnal activity in the cathemeral red-fronted lemur (Eulemur fulvus rufus), with observations during a lunar eclipse, Am. J. Primatol., 53, 69-78, 2001.

Duellman, W. E. and Trueb, L.: Biology of Amphibians, The Johns Hopkins University Press, Baltimore, 1994.

Farbridge, K. J. and Leatherland, J. F.: Lunar cycles of coho salmon, Oncorhynchus kisutch. I. Growth and feeding, J. Exp. Biol., 129, 165-178, 1987.

Fitzgerald, G. J. and Bider, J. R.: Influence of moon phase and weather factors on locomotory activity in Bufo americanus, Oikos, 25, 338-340, 1974.

Gannon, M. R. and Willing, M. R.: The effect of lunar illumination on movement and activity of the red fig-eating bat (Stenoderma rufum), Biotropica, 29, 525-529, 1997.

Gomez, D., Richardson, C., Lengagne, T., Plénet, S., Joly, O., Léna, J. P., and Théry, M.: The role of noctural vision in mate choice : females prefer conspicuous males in the European tree frog ( Hyla arborea), Proc. R. Soc. B, 276, 2351-2358, 2009.

Gosner, K. L.: A simplified table for staging anuran embryos and larvae with notes on identification, Herpetologica, 16, 183-190, 1960.

Gosner, K. L. and Rossman, D. A.: Eggs and larval development of the treefrogs Hyla crucifer and Hyla ocularis, Herpetologica, 16, 225-232, 1960.

Gibbons, J. W. and Bennett, D. H.: Determination of anuran terrestrial activity patterns by a drift fence method, Copeia, 1974, 236-243, 1974.

Grant, R. A., Chadwick, E. A., and Halliday, T.: The lunar cycle: a cue for amphibian reproductive phenology?, Anim. Behav., 78, 349-357, 2009.

Jaeger, R. C. and Hailman, J. P.: Activity of Neotropical frogs in relation to ambient light, Biotropica, 13, 59-65, 1981.

Jaksic, F. M., Seib, R. L., and Herrera, C. M.: Predation of Barn Owl (Tyto alba) in Mediterranean habitats of Chile, Spain, and California: a comparative approach, Am. Mid. Nat., 107, 51-162, 1982.

John-Alder, H. B., Morin, P. J., and Lawler, S.: Thermal physiology, phenology and distribution of tree frogs, Am. Nat., 132, 506$520,1988$. 
Julien-Laferrière, D.: The Influence of Moonlight on Activity of Woolly Opossums (Caluromys philander), J. Mammal., 78, 251255, 1997.

Kiesecker, J. M. and Skelly, D. K.: Choice of oviposition site by gray treefrogs: the role of potential parasitic infection, Ecology, 81, 2939-2943, 2000.

Kotler, B.: Risk of predation and the structure of desert rodent communities, Ecology, 65, 689-701, 1984.

Kotler, B. P., Brown, J. S., and Hasson, O.: Factors affecting gerbil foraging behavior and rates of owl predation, Ecology, 72, 22492260, 1991.

Krisciunas, K. and Schaefer, B. E.: A model of the brightness of moonlight, Publ. Astron. Soc. Pac., 103, 1033-1039, 1991.

Landreth, H. F. and Ferguson, D. E.: Newts: Sun-Compass Orientation, Science, 158, 1459-1461, 1967a.

Landreth, H. F. and Ferguson, D. E.: Newt Orientation by Suncompass, Nature, 215, 516-518, 1967b.

Lapini, L.: Hyla intermedia Boulanger, 1882, in: Fauna d'Italia: Amphibia, edited by: Lanza, B., Andreone, F., Bologna, M. A., Corti, C., and Razzetti, E., Calderini Edizioni, Bologna, 333338, 2007.

Lima, S. L. and Dill, L. M.: Behavioral decisions made under the risk of predation: a review and prospectus, Can. J. Zool., 68, 619640, 1990.

Lipps, K. R., Reaser, J. K., Young, B. E., and Ibez, R.: Amphibian monitoring in Latin America - A protocol manual, Society for the Study of Amphibians Reptiles, Herpetological Circular No 30, 115 pp., 2001.

Lockhard, R. B.: Seasonal change in the activity pattern of Dipodomys spectabilis, J. Mammal., 59, 563-568, 1978.

Lockard, R. B. and Owings, D. H.: Moon-related surface activity of Bannertail (Dipodomys spectabilis) and Fresno (D. nitratoides) kangaroo rats, Anim. Behav., 22, 262-273, 1974.

Longcore, T. and Rich, C.: Ecological light pollution, Front. Ecol. Environ., 2, 191-198, 2004.

Luiselli, L., Filippi, E., and Capula, M.: Geographic variation in diet composition of the grass snake (Natrix natrix) along the mainland and an island of Italy: the effects of habitat type and interference with potential competitors, Herpetol. J., 15, 221-230, 2005.

Magnhagen, C.: Predation risk as a cost of reproduction, Trends Ecol. Evol., 183-186, 1991.

Mantero, F. M.: Primi contributi alla conoscenza del territorio della Riserva Naturale Regionale Monterano, Canale Monterano, Italy, Riserva Naturale Regionale Monterano, 2006.

Martof, B.: Home range and movements of the green frog, Rana clamitans, Ecology, 34, 529-543, 1953.

Mielke, P. W., Berry, K. J., and Johnson, E. S.: Multi-response permutation procedures for a priori classifications, Commun. Stat. Theory Methods, 5, 1409-1424, 1976.

Morgan, E.: The moon and life on Earth, Earth, Moon and Planets, 85-86, 279-290, 2001.

Mougeot, F. and Bretagnolle, V.: Predation risk and moonlight avoidance in nocturnal seabirds, J. Avian Biol., 31, 376-386, 2000.

Murray, D. L., Roth, J. D. and Wirsing, A. J.: Predation risk avoidance by terrestrial amphibians: The role of prey experience and vulnerability to native and exotic predators, Ethology, 110, 635647, 2004.
Nash, L. T.: Influence of moonlight levels on travelling and calling patterns in two sympatric species of Galago in Kenia, in: Current perspectives in primate social dynamics, edited by: Taub, D. M. and King, F. A., Van Nostrand Reinhold Co., New York, 357367, 1986.

Naylor, E.: Marine Animal Behaviour in Relation to Lunar Phase, Earth Moon Planets, 85-86, 291-302, 2001.

Nelson, D.: Gull predation on Cassin's Auklet varies with the lunar cycle, Auk, 106, 495-497, 1989.

Olson, D. H.: Predation on Breeding Western Toads (Bufo boreas), Copeia, 1989, 391-397, 1989.

Oseen, K. L. and Wassersug, R. J.: Environmental factors influencing calling in sympatric anurans, Oecologia, 133, 616-625, 2002.

Parsons, K. N., Jones, G., and Greenaway, F.: Swarming activity of temperate zone microchiropteran bats: effects of season, time of night and weather conditions, J. Zool. London, 261, 257-264, 2003.

Paton, P. W. C. and Harris, R. N.: Egg mass and nest counts, in: Amphibian ecology and conservation, edited by: Dodd Jr., C. K., Oxford University Press, New York, 282-298, 2010.

Pechmann, J. H. K. and Semlitsch, R. D.: Diel activity patterns in the breeding migrations of winter-breeding anurans, Can. J. Zool., 64, 1116-1120, 1986.

Penteriani, V., Kuparinen, A., Delgado, M. M., Lourenço, R., and Campioni, L.: Individual status, foraging effort and need for conspicuousness shape behavioural responses of a predator to moon phases, Anim. Behav., 82, 413-420, 2011.

Petranka, J. W.: Observations on nest site selection, nest desertion, and embryonic survival in marbled salamanders, J. Herpetol., 24, 229-234, 1990.

Ralph, C. L.: A diurnal activity rhythm in Plethodon Cinereus and its modification by an influence having a lunar frequency, Biol. Bull., 113, 188-197, 1957.

Resetarits, W. J. and Wilbur, H. M.: Choice of oviposition site by Hyla chrysoscelis: role of predators and competitors, Ecology, 70, 220-228, 1989.

Robertson, D.: The light-dark cycle and a nonlinear analysis of lunar perturbations and barometric pressure associated with the annual locomotor activity of the frog, Rana pipiens, Biol. Bull., 154, 302-321, 1978.

Rödel, M. O. and Ernst, R.: Measuring and monitoring amphibian diversity in tropical forests. I. An evaluation of methods with recommendations for standardization, Ecotropica, 10, 1-14, 2004.

Salthe, S. N. and Mecham, J. S.: Reproductive and courtship patterns, in: Physiology of the Amphibia, edited by: Lofts, B., Academic Press, New York, 309-521, 1974.

Schneider, H., Sofianidou, T. S., and Kyriakopoulou-Sklavounou, P.: Calling Behavior and Calls of Rana dalmatina (Anura, Ranidae) in Greece, Zool. Jb. Physiol., 92, 231-243, 1988.

Schwarzkopf, L. and Brooks, R. J.: Nest-site selection and offspring sex ratio in painted turtles, Chrysemys picta, Copeia, 1987, 5361, 1987.

Semlitsch, R. D.: Differentiating migration and dispersal processes for pond-breeding amphibians, J. Wild. Manag., 72, 260-267, 2008.

Sinsch, U.: Migration and orientation in anuran amphibians, Ethol. Ecol. Evol., 2, 65-79, 1990.

Skutelsky, O.: Predation risk and state-dependent foraging in scorpions: effects of moonlight on foraging in the scorpion Buthus 
occitanus, Anim. Behav., 52, 49-57, 1996.

Stebbins, R. C. and Cohen, N. W.: A Natural History of Amphibians, Princeton University Press, New Jersey, 1997.

Tuttle, M. D. and Ryan, M. J.: The role of synchronized calling, ambient light, and ambient noise, in anti-bat-predator behavior of a treefrog, Behav. Ecol. Sociobiol., 11, 125-131, 1982.

Van Gelder, J. J. and Hoedemaekers, H. C. M.: Sound activity and migration during the breeding period of Rana temporaria L. $R$. arvalis Nilsson, Pelobates fuscus Laur. and Rana esculenta L., J. Anim. Ecol., 40, 559-568, 1971.

Vignoli, L.: Struttura di comunità e ripartizione differenziale delle risorse in una biocenosi ad anfibi, Ph.D. Dissertation, University "Roma Tre", Rome, Italy, 2003.

Vignoli, L., Luiselli, L., and Bologna, M. A.: Seasonal patterns of activity and community structure in an amphibian assemblage at a pond network with variable hydrology, Acta Oecol., 31, 185192, 2007a.
Vignoli, L., Luiselli, L., and Bologna, M. A.: Spatio-temporal resource use at a microhabitat scale in an amphibian community at a pond in Mediterranean Central Italy, Vie et Milieu, 57, 159164, 2007b.

Vignoli, L., Luiselli, L., and Bologna, M. A.: Dietary patterns and overlap in an amphibian assemblage at a pond in Mediterranean Central Italy, Vie et Milieu, 59, 47-57, 2009.

Walls, G. L.: The vertebrate eye and its adaptive radiation, Cranbrook Institute of Science, Oxford, England, 1942.

Wells, K. D.: The ecology and behaviour of amphibians, University of Chicago Press, Chicago, 2007.

Wolfe, J. L. and Tan Summerlin, C.: The influence of lunar light on nocturnal activity of the old-field mouse, Anim. Behav., 37, 410-414, 1989.

Yetman, C. A. and Ferguson, J. W. H.: Spawning and non-breeding activity of adult giant bullfrogs (Pyxicephalus adspersus), Afr. J. Herpetol., 60, 1-17, 2011. 